\title{
Jesús Ignacio Delgado, Víctima y el derecho a la no discriminación por diversidad afectivo-sexual
}

(2020) Tirant lo Blanch

Valencia, $98 \mathrm{pp}$.

\author{
David García García \\ Universidad Carlos III de Madrid \\ ORCID ID 0000-0001-8322-9676 \\ david.garcia.garcia@uc3m.es
}

\section{Cita recomendada:}

García García, D. (2021). Jesús Ignacio Delgado, Víctima y el derecho a la no discriminación por diversidad afectivo-sexual. Eunomía. Revista en Cultura de la Legalidad, 20, pp. 509-512.

doi: https://doi.org/10.20318/eunomia.2021.6095

Seguramente la imagen más inmediata que se nos presenta al pensar sobre la relación entre Derecho y cine sea la representación cinematográfica del crimen y el castigo. La comisión de un delito, la investigación policial, el juicio, las deliberaciones del jurado, la prisión e, incluso, la ejecución dotan, en conjunto o en exclusiva, de argumento y contexto a un sin fin de películas. Pero el universo jurídico no se agota en el delito y la pena, proceso mediante, por lo que las cuestiones y problemáticas de tinte jurídico abordadas por el cine se alejan de una versión digamos 'criminalista' del género jurídico, suponiendo que éste exista como tal. Una reflexión más pausada nos hará recordar el tratamiento de cuestiones de Derecho privado, como el matrimonio, el divorcio o la patria potestad; cuestiones de naturaleza política, procesos electorales, corrupción política o crisis financieras; y tantos otros temas como la discriminación racial, la violencia de género, la eutanasia, el aborto, la libertad de expresión o la libertad sexual. El mundo del Derecho, ya sea de manera principal o secundaria, se incorpora al guion de los films de una manera natural. Esta relación es tan antigua como el cinematógrafo, pero ¿acaso podría ser de otra manera? El cine, antes que nada, pretende contar historias y, lo queramos o no, nuestras historias están atravesadas por el Derecho.

Así las cosas, no sorprende que los estudios sobre Derecho y cine estén en auge. Nosotros, que quisimos tanto a Atticus Finch (Javier de Lucas, 2020), Cine, 
series y derecho de empresa (José Luis Luceño Oliva, 2020), Sueños en movimiento. Derecho, historia y estado en la literatura y el cine (1945-1969) (Enrique San Miguel Pérez, 2020) o La formación del jurista a través del cine (Carmen Ortiz y Guillermo José Velasco (dirs.), 2020) son algunos de los trabajos publicados sobre esta temática durante el pasado año 2020. En lo que va de año 2021 ya han aparecido Cine y Derecho. Togas en la gran pantalla (Rafael de Mendizábal) y la nueva edición de la obra Derecho y cine en 100 películas, de Benjamín Rivaya.

Estos estudios sobre Derecho y cine proporcionan diversas líneas de interés para el jurista. Sin ánimo de ser exhaustivo, una de ellas sería su capacidad didáctica. La utilización de películas -hábilmente seleccionadas y sin pretender sustituir la lectura de textos- es, sin duda, un recurso atractivo y eficaz para acercar a los estudiantes de Derecho a algunas problemáticas, especialmente en aquellas áreas donde agudos guionistas suplen nuestra limitada imaginación al plantear dilemas teóricos y prácticos que afectan al Derecho. En ocasiones, este interés traspasa el horizonte didáctico y se traslada y asienta en el debate especializado, como ocurre con la conocida como «Doctrina Julia Roberts», bautizada por el profesor J. J. Moreso (2009) en atención a una intervención ${ }^{1}$ del personaje interpretado por esta actriz en la película El informe pelícano.

El profesor Benjamín Rivaya nos da otra clave del interés de estos estudios: «el saber popular sobre el Derecho tiene su origen en el cine» (2017, p. 150). Si esto es así, si la pantalla, ya sea a través del cine, las series o la televisión, construye y da forma a nuestra creencia colectiva sobre el fenómeno jurídico, esta es una realidad que el estudioso del Derecho no debe desaprovechar.

Esta toma de conciencia por parte del jurista del cine como constructor de imaginarios sitúa a los estudios sobre Derecho y cine ante una relación de doble sentido, frente a un camino que se recorre en dos direcciones. El viaje de ida transita desde el Derecho hasta la gran pantalla, colocándonos frente al espejo y ofreciéndonos una visión particular de lo jurídico. El de vuelta, desde el cine al Derecho, se nos presenta más difuso y sinuoso.

El interés del trabajo realizado por Jesús Ignacio Delgado en Víctima y el derecho a la no discriminación por diversidad afectivo-sexual (2020) radica precisamente en ofrecernos el viaje al completo. Tras este título se esconde el relato acerca de cómo la película Víctima representó las consecuencias sociales de la legislación penal británica y logró jugar «un papel relevante en la reforma legal sobre la despenalización de la homosexualidad en Inglaterra» (p. 11). Un relato que se despliega en tres actos: 1. la publicación del Informe Wolfenden (1957); 2. el estreno de la película Víctima (1961); y 3. la promulgación de la nueva Sexual Offences Act (1967).

El primero, desarrollado en el capítulo 2 -El contexto histórico - nos presenta una sociedad británica caracterizada por unas «estructuras de pensamiento rancias y mojigatas de la estricta y puritana moral victoriana» (Delgado, 2020, p. 18). Una sociedad que acumulaba una larga trayectoria en la persecución penal de la homosexualidad. Si bien es cierto que los últimos hombres que pagaron con su vida -a manos del Estado- las prácticas homosexuales lo hicieron en 1835, la cárcel podía seguir siendo su destino durante la primera mitad del siglo $X X-a$ pesar de los esfuerzos y desafíos planteados por el denominado Grupo de Bloomsbury a la férrea

\footnotetext{
1 Curiosamente, la intervención de Darby Shaw, la estudiante de Derecho -interpretada por Julia Roberts- que da nombre a la teoría del profesor Moreso, se refiere a la inconstitucionalidad de la ley penal contra la sodomía del Estado de Georgia.
} 
moral victoriana-. Una persecución que se intensificó especialmente tras la Segunda Guerra Mundial.

Factores como la constatación de que la homosexualidad no era un fenómeno minoritario -gracias a los estudios sobre comportamiento sexual del investigador Alfred Kinsey-, el aumento de detenciones por sodomía y la influencia mediática de algunos de estos casos, propiciaron la creación en 1954 del Comité sobre Delitos de Homosexualidad y Prostitución, con el encargo de analizar posibles modificaciones legales. El resultado es el conocido como Informe Wolfenden (1957), que toma su nombre del presidente de la comisión: Sir John Wolfenden, y en el que sus miembros recomendaban que "[e]l comportamiento homosexual entre adultos que consientan en ello deje de constituir un delito» (p. 39).

La distinción entre moral y Derecho, entre pecado y delito, entre público y privado dieron contenido al informe y forma al problema del moralismo legal, que tan agudamente ha estudiado el profesor Delgado y que incorpora a este texto a través del pensamiento de autores como Fitzjames Stephen, John Stuart Mill, Lord Devlin o Herbert Hart.

Es en el segundo acto -capítulo 3. La película- en el que comienza el análisis del tipo 'Derecho y cine' propiamente dicho, y es que a juicio del autor "[l]as declaraciones de principios recogidas en el Informe Wolfenden son la referencia a la que acudirán los guionistas del film Víctima para hacer hablar a los protagonistas» (pp. 37-38). Dirigida por Basil Dearden y protagonizada por Dirk Bogarde, el estreno de la película tuvo lugar en el año 1961. Para evitar la censura y atraer la atracción de un mayor público la productora no tuvo reparos en presentarla como una película acerca del chantaje, pero nada más lejos de las intenciones del director y del productor quedarse ahí. El chantaje al que se veían expuestos los homosexuales para mantener en secreto su condición es el medio para mostrarnos la injusticia de la ley. A través de la historia de un exitoso abogado de clase alta que se enfrenta a esta trampa auspiciada por vía legal, la película nos desvela e introduce en la cotidianidad de este mundo 'secreto'. El género, el texto o el estilo son utilizados «conscientemente por los guionistas para ayudar a la audiencia a comprender varios aspectos de los temas relacionados con la reforma legal» (p. 53). Lo que se pretendía era poner a la sociedad británica frente a sí misma, frente a sus prejuicios e hipocresías, y convencer a los espectadores de la necesidad de cambiar la ley.

Si hay un personaje que evidencia las miserias de la ley que penalizaba la homosexualidad es el comisario de policía encargado de la investigación del chantaje. Afirmaciones como: "ese chico no es un ladrón, creo que es más una víctima que un delincuente», "más del $90 \%$ de los casos de chantaje son de origen homosexual», «una ley que envía a los homosexuales a la cárcel ofrece oportunidades para el chantaje», "si la ley castigara todas las anormalidades estaríamos muy ocupados", puestas en boca del representante del 'aparato coercitivo del Estado', invitaban desde luego a la reflexión del espectador.

El tercer acto -capítulo 4. Paisaje tras la película. ¿Qué supuso Víctima para la sociedad inglesa? - recorre el camino de vuelta, el que va desde el cine hasta el Derecho, a través del escurridizo concepto de cambio social. Habría de transcurrir una década hasta que los legisladores británicos asumieran e implementaran las recomendaciones de despenalización de la homosexualidad -por el momento solo en el ámbito privado- del Informe Wolfenden, en 1967 con la Sexual Offences Act. El proceso de despenalización no finalizará hasta iniciado el siglo XXI. 
Los cambios sociales son fenómenos complejos. Resulta difícil cuantificar el grado de incidencia de una película o de una novela, consideradas individualmente, en las conciencias de los espectadores y lectores. Pero sí podemos hacernos una idea de su importancia a través de las experiencias personales de quienes lo vivieron. Me permito tomar un último testimonio recogido por el profesor Delgado, que corresponde a una carta remitida en 1968 por Lord Arran, el que fuera promotor del proyecto de modificación legal, al protagonista de Víctima, Dirk Bogarde:

El cambio en la opinión popular como lo muestran las encuestas (del $48 \%$ al $63 \%$ a favor de la reforma) se debió en gran parte a sus dos películas El sirviente y Víctima, o eso creo.

Es reconfortante pensar que tal vez un millón de hombres ya no viven con miedo (pp. 84-85).

El trabajo de Jesús Ignacio Delgado construye este viaje que me he limitado a esbozar desde el rigor y el entusiasmo. El entusiasmo de un apasionado del cine que encuentra un hilo conductor entre dos mundos. El rigor de un estudioso de la fructífera y siempre problemática relación entre el Derecho y la moral. Sirva su lectura para recuperar el film y poner en valor la labor de quienes, como el equipo de Víctima, nos sitúan frente al espejo y propician la labor terapéutica del cine.

\section{Bibliografia}

Rivaya, B. (2017). Derecho y cine todo lo que siempre quiso saber sobre el derecho y nunca se atrevió a preguntar. Ratio Juris UNAULA, 1(3), 135-151.

Moreso, J. J. (2009). La doctrina Julia Roberts y la objetividad del derecho. En La Constitución: modelo para armar (pp. 175-181). Madrid, España: Marcial Pons. 